\title{
EL PENSAMIENTO ECONÓMICO EN LA ANTIGUA GRECIA
}

\author{
JESÚS HUERTA DE SOTO* \\ I
}

En la Grecia clásica se inicia la epopeya intelectual que construyó los cimientos de la civilización occidental. Sin embargo, desgraciadamente, los pensadores griegos fracasaron en su intento a la hora de comprender los principios esenciales del orden espontáneo del mercado y del proceso dinámico de cooperación social que les rodeaba. Si bien hay que reconocer las grandes aportaciones realizadas por los griegos en el campo de la epistemología, la lógica, la ética e incluso de la concepción del derecho natural, fracasaron lamentablemente a la hora de entender que también debía desarrollarse una disciplina, la ciencia económica, que estuviera dedicada a estudiar los procesos espontáneos de cooperación social que constituyen el mercado. Peor aún, con el surgimiento de los primeros intelectuales, aparece también la tradicional simbiosis y complicidad entre pensadores y gobernantes. Ya desde un principio los intelectuales, en su gran mayoría, abrazan la bandera del estatismo, y sistemáticamente minusvaloran, e incluso critican y denigran la floreciente sociedad mercantil, comercial y artesanal que les rodeaba. Quizá hubiera sido mucho pedir que, con los mismos albores del conocimiento filosófico y científico, los griegos entendieran también desde un principio al menos los rudimentos de una disciplina que, como la economía política, es la más joven de todas la ciencias y tiene como misión el estudio de realidades tan abstractas y difíciles de comprender como la del orden espontáneo del

* Catedrático de Economía Política de la Universidad Rey Juan Carlos de Madrid. 
mercado. Pero lo que sí llama la atención es cómo los griegos, al igual que los intelectuales de hoy, no pudieron evadirse de la arrogancia cientificista de creerse legitimados para imponer a sus conciudadanos sus particulares puntos de vista, proponiendo para ello la utilización de la coacción sistemática del gobierno. La historia se repite una y otra vez y es muy poco lo que, incluso hoy, hemos avanzado en este sentido.

\section{II EL CONTEXTO HISTÓRICO POLÍTICO}

El paralelismo se da también, no sólo en relación con las simpatías estatistas de los pensadores sino, además, respecto del contexto de rivalidad entre dos concepciones radicalmente opuestas relativas al gobierno y a la libertad individual. En efecto, a lo largo de gran parte del siglo XX el mundo y la sociedad en general se han encontrado divididos: por un lado, la concepción liberal basada en el gobierno limitado, el respeto a la sociedad civil y la libertad y responsabilidad individual (representada, al menos en términos relativos, por la sociedad norteamericana); por otro lado, el socialismo imperante que pretende recurrir al estado para imponer por la fuerza a la sociedad civil las más variadas utopías (representado durante gran parte del siglo XX por la ya extinta Unión Soviética). También en la Grecia clásica cabe identificar dos polos igualmente opuestos. Por un lado, la relativamente más liberal y democrática ciudad de Atenas, que es capaz de acoger una floreciente vida comercial y artesanal, en un orden espontáneo de cooperación social basado en el respeto e igualdad ante la ley. Frente a Atenas, destaca la ciudad de Esparta, profundamente militarista, y en la cual la libertad individual es prácticamente inexistente, pues todos los recursos se consideran que han de estar subordinados al estado. Llama la atención cómo, de manera invariable, los más importantes y destacados pensadores y filósofos atenienses no cesaron de criticar, fustigar y minusvalorar el orden comercial que les rodeaba y gracias al cual vivían, aprovechando, por contra, cada oportunidad para ensalzar el totalitarismo estatista que representaba Esparta. Parece 
como si los intelectuales de entonces, al igual que los de ahora, no pudieran sufrir el hecho de que, aun considerándose más sabios, no fueran capaces de cosechar en términos económicos los resultados de lo que ellos consideraban que era su propia valía, ni de resistirse a la tentación de imponer a sus conciudadanos sus particulares puntos de vista sobre lo que estaba bien o mal, proponiendo para ello en cada momento la utilización del poder coactivo del estado.

El reconocimiento de esta realidad no nos debe llevar al engaño de pensar que las polis relativamente más libres no fueran también víctimas, en muchas ocasiones, del estatismo. Por ejemplo, muchos políticos no dudaron a la hora de justificar que Atenas emprendiera políticas imperialistas, llegando incluso, como hizo Pericles en el siglo V a.C., a malversar el erario público para emprender obras faraónicas (como la del Partenón, que fue construido desviando recursos que habían sido acumulados con gran esfuerzo por diversas polis para otros fines de carácter defensivo), y a intentar convencer a sus ciudadanos de que lo importante era someterse a la voluntad del estado, debiendo éstos preguntarse en cada momento qué podían hacer por el estado de Atenas en vez de cuestionarse qué es lo que podrían conseguir de él (cantinela estatista que veinticinco siglos después repetiría y haría famosa el Presidente Kennedy). Además, las polis relativamente más libres no dejaron de estar sometidas a un ciclo político que, por paradójico y curioso que parezca, sigue afectando a nuestras sociedades en los tiempos actuales. En efecto, tras períodos de mayor libertad civil basada en el cumplimiento de las leyes en sentido material, invariablemente las ciudades entraban en crisis víctimas de la demagogia y la agitación dirigida por unos pocos y orientada a explotar a unos grupos sociales en favor de otros supuestamente más numerosos y menos privilegiados; todo lo cual daba lugar a importantes tensiones sociales, económicas y políticas que eventualmente terminaban en graves desórdenes y conflictos civiles que, a su vez, eran la justifición para incrementar el poder del estado encarnado en cada circunstancia histórica en líderes populistas sin escrúpulos que siempre se hacían coronar a sí mismos como «salvadores de la patria». 
III

\section{ALGUNOS EMBRIONARIOS INTENTOS DE ANÁLISIS ECONÓMICO}

Es muy difícil conocer con precisión lo que pensaron los primeros filósofos griegos, pues son muy pocos y muy fragmentados los documentos que nos han llegado hasta hoy. Existen, no obstante, algunos inicios esperanzadores que, de haber sido continuados, podrían haber hecho posible un incipiente desarrollo de la teoría sobre el orden espontáneo del mercado.

Por ejemplo, Hesíodo, ya en el siglo VIII a.C., indicaba en sus poemas que la escasez es una constante en todas las acciones humanas y cómo la misma determina la necesidad de asignar de manera eficiente los recursos disponibles. Es más, Hesíodo se refiere a la competencia por emulación, que él denomina «buen conflicto", como una fuerza vital de tipo empresarial que hace posible superar en muchas circunstancias los grandes problemas que plantea la escasez de recursos. Además, para Hesíodo, la competencia solo es posible si se respeta la ley y la justicia, que inducen el orden y la armonía dentro de la sociedad. En este sentido, Hesíodo - y también en cierta medida Demócrito- se encuentra mucho más cerca de la correcta concepción del orden espontáneo del mercado de lo que después lo estarán Sócrates, Platón e incluso el propio Aristóteles.

Tras Hesíodo, destacan los filósofos sofistas que, a pesar de la mala prensa que han tenido hasta hoy, fueron ciertamente mucho más liberales, al menos en términos relativos, que aquellos grandes filósofos que vinieron después. En efecto, los sofistas simpatizaron con el comercio, el ánimo de lucro y el espíritu empresarial, desconfiando del poder centralizado y omnímodo de los gobiernos de las ciudades estado. Y aunque hay que reconocer que en ocasiones cayeron en un relativismo semejante al patrocinado por los postmodernistas del mundo actual, desde el punto de vista de la defensa de la libertad del individuo frente al gobierno superaron con mucho a los pensadores socráticos posteriores. Llama finalmente la atención cómo la arrogancia cientificista a favor del estatismo característica de la mayoría de los intelectuales hasta hoy, se ha cuidado de desprestigiar por 
sistema a los sofistas — siempre políticamente «incorrectos»tachándolos de pensadores poco coherentes y tramposos.

Posteriormente otros pensadores más modernos, como Protágoras en la época de Pericles, teorizaron sobre la necesidad de la cooperación social, insistiendo en que «el hombre es la medida de todas las cosas», lo que, llevado filosóficamente a sus últimas consecuencias, podría haber dado lugar al surgimiento natural del subjetivismo y del individualismo metodológico, imprescindibles puntos de partida de todo análisis económico de los procesos sociales. También Tucídides, maestro de historiadores, parece concebir mejor que muchos de sus coetáneos el carácter espontáneo y evolutivo del orden social, aparte de haber sabido resaltar como nadie, en su resumen de la oración fúnebre de Pericles, el carácter relativamente más liberal de la sociedad ateniense. Por último, debemos mencionar a Demóstenes, el gran campeón de la libertad de la Hélade frente al despotismo del tirano Filipo. No es una casualidad que Demóstenes entendiera la esencia consuetudinaria y evolutiva del derecho, y en ese sentido fuera capaz de superar la dicotomía reduccionista establecida por los griegos entre el mundo físico (natural) y el mundo supuestamente artificial de las leyes o convenciones: y es que, en general, los griegos no fueron capaces de darse cuenta de que en el cosmos natural debe incluirse también el orden espontáneo del mercado y las relaciones sociales que estudia la economía, pues para ellos todo lo relacionado con la sociedad, no era sino un resultado siempre artificial y deliberado de sus organizadores (a ser posible dictadores-filósofos tipo Platón).

El punto de vista subjetivista, en torno al cual habrá de girar toda la ciencia económica moderna, se encuentra, por ejemplo, en la definición de la riqueza que Jenofonte presenta en su Economico, cuando define la propiedad como «lo provechoso para la vida de cada cual». Es más, puede considerarse que Jenofonte es el primer tratadista que da entrada al concepto de eficiencia dinámica, consistente en incrementar la hacienda comerciando y tratando empresarialmente con ella (junto al concepto estático de eficiencia centrado en evitar el despilfarro y que según Jenofonte se lograría manteniendo en perfecto orden la hacienda familiar). 
Pero a pesar de estos inicios prometedores, y de las grandes aportaciones realizadas en otros campos del pensamiento filosófico y científico (y quizás, precisamente por ello) en general los filósofos griegos cayeron en la fatal arrogancia del intelectual cientista. Ésta les cegó por completo a la hora de reconocer el mercado y el orden social evolutivo, haciéndoles caer en los brazos del estatismo y convirtiendo en "políticamente correcto» el desprecio por la actividad mercantil y comercial de sus coetáneos, así como la crítica despiadada a los pensadores (sofistas o no) relativamente más liberales.

\section{IV \\ LOS CASOS ESPECIALMENTE PELIGROSOS DE SÓCRATES, PLATÓN E, INCLUSO, ARISTÓTELES}

La característica común más importante a nuestros efectos de los tres filósofos más grandes de la antigua Grecia es que no fueron capaces de comprender la naturaleza del floreciente proceso mercantil y comercial que se desarrollaba entre las diferentes ciudades o polis griegas (tanto de la propia Grecia, como de Asia Menor y del resto del Mediterráneo). Hablaron de la economía desde el instinto, más que desde la observación y la razón. Desdeñaron la labor de artesanos y comerciantes, minusvalorando la importancia de su trabajo diario y disciplinado. Se inicia así, de la mano de estos filósofos, la clásica oposición de los intelectuales ante todo lo que suponga comercio, industria y beneficio empresarial. Esta "mentalidad anticapitalista» (Mises) habrá de ser una constante entre los pensadores «ilustrados» a lo largo de toda la historia intelectual del género humano desde entonces hasta nuestros días.

Una ilustración paradigmática de esta oposición intelectual a todo lo que signifique beneficio empresarial, industria o mercado es la del filósofo Sócrates. De Sócrates hay que resaltar su tono arrogante y falsa modestia puesta de manifiesto en su discurso apologético de defensa ante el jurado que le juzgaba y que ha llegado a nosotros a través de Platón. No hay duda de su mala influencia entre los jóvenes de la ciudad de Atenas, a los que 
captaba ridiculizando el proyecto vital de sus padres, sacrificadamente dedicados al esfuerzo diario y honesto en los ámbitos del comercio, la artesanía y el mercado. Pero para Sócrates el ideal vital había que situarlo en la búsqueda de la «virtud», entendida como el desprecio a las riquezas materiales y, en concreto, al beneficio empresarial. Sócrates aprovechaba cada oportunidad para presumir de su pobreza e idealizar las supuestas virtudes del estado totalitario de Esparta, que entonces representaba los ideales opuestos a los de Atenas. Es más, en su discurso de defensa, levanta la indignación del jurado cuando proclama que sus servicios al estado de Atenas eran tantos, que en vez de un juicio debería recibir una pensión vitalicia pagada por todos (¡en forma de alimentos financiados por la ciudad mientras durase su vida!). Y lo que es aún más grave, la estatolatría de Sócrates es tan obsesiva que le lleva a confundir el derecho positivo emanado de la ciudad-estado con el derecho natural. Para él hay que obedecer todas las leyes positivas emanadas del estado, aunque sean «contra natura», poniendo así los fundamentos filosóficos del positivismo legal en el que se fundamentarán todas las tiranías que han surgido a partir de él en la historia. En suma, desde el punto de vista de la teoría científica de los procesos de mercado la influencia de Sócrates es, ciertamente, desastrosa. Inicia e impulsa la tradición intelectual anticapitalista. Manifiesta su absoluta incomprensión sobre el orden espontáneo del mercado al que precisamente se debía la prosperidad ateniense que hizo posible que tanto Sócrates como el resto de los filósofos de su escuela pudieran permitirse el lujo de no trabajar y dedicarse a pensar. Y como pago a ese entorno de relativa libertad y prosperidad, Atenas sólo recibió de Sócrates el desprecio y la incomprensión. Hemos de referirnos, finalmente, a la más que interesada autoinmolación de este filósofo. Él mismo reconoce que a su edad y con sus achaques poco hubiera podido hacer en el corto espacio de vida que habría de quedarle de aceptar el destierro que le sirvieron en bandeja sus jueces y verdugos. Por eso decide pasar a la posteridad haciéndose la víctima de una supuesta injusticia, cuando en realidad su muerte fue un suicidio, tan interesado como oportuno, fraguado por una mente arrogante y privilegiada que, además, pretendió con el mismo legitimar el 
culto al estatismo opresor desprestigiando el individualismo liberal.

Teniendo un maestro como Sócrates no es de extrañar que Platón ahondara aún más en sus errores. Platón construye la peligrosísima fundamentación filosófica del estatismo más antihumano, en la que habrán de beber directa o indirectamente todos los tiranos que hasta nuestros días han oprimido a la humanidad. En Platón se encarna el más puro ejemplo del más grave pecado intelectual en que puede caer un científico: el de la «fatal arrogancia» (Hayek) de creerse más sabio que el resto de sus congéneres $y$, por tanto, considerarse legitimado para imponerles por la fuerza sus particulares puntos de vista. Son características propias de Platón sus ataques a la propiedad privada; su alabanza de la propiedad común; su desprecio por la institución de la familia tradicional; su concepto corrupto de la justicia; su teoría estatista y nominalista del dinero; y, en suma, su ensalzamiento de los ideales del estado totalitario de Esparta. Todas éstas son características típicas del intelectual que se cree más sabio y superior a los demás y que, sin embargo, ignora hasta los más elementales principios del orden espontáneo del mercado que hace posible la civilización. Además, Platón, ensalza el interés del estado frente al de los particulares, llegando incluso al extremo de intentar llevar a la práctica sus utópicos ideales de tiranía estatal. Afortunadamente, él y sus discípulos fracasaron, como no podía ser de otra manera, en todos sus intentos tanto en Siracusa como en el resto de Grecia. Finalmente, incluso en el ámbito de la epistemología las aportaciones de Platón fueron a la larga letales. Así, su supuesto esencialismo, da entrada, por la puerta de atrás, al más grosero historicismo positivista, cuando en el ámbito de lo social pretende extraer las esencias conceptuales del estudio de la historia, poniendo así las bases de la filosofía histórico-positivista que tanto daño ha hecho lastrando el desarrollo de la ciencia social incluso hasta nuestros días. En suma, con Platón adquiere carta de naturaleza el ideal intelectual del científico arrogante que pretende convertirse en un «ingeniero social» para moldear la sociedad a su antojo. Enfoque que se refuerza, aún más si cabe, con la escuela del matemático Pitágoras, que consideraba que la 
virtud se encuentra en la «igualdad» y en el «equilibrio» que continuamente observaba en sus fórmulas y principios matemáticos, y que creía debían ser extrapoladas al cuerpo social.

Aunque Aristóteles no cae en los extremos socialistas de Platón también fracasa, estrepitosamente, a la hora de comprender en términos científicos el orden espontáneo del mercado. Filósofo al servicio del peor dictador de su época (Filipo de Macedonia, que acabó con el sutil entramado de ciudades-estado independientes que constituían la antigua Hélade) fue preceptor y maestro de un déspota tan tirano y alocado como Alejandro Magno. No es de extrañar que Aristóteles tampoco pudiera librarse del pecado de arrogancia intelectual que afectó a Sócrates y, sobre todo, a Platón: fue también un nostálgico del estatismo de Esparta y de todo lo que representaba el totalitarismo de esa ciudad-estado. Es cierto que no cayó en los extremos platónicos, que defendió la propiedad privada, y que llegó a intuir, incluso, la teoría subjetiva del valor en su distinción entre el «valor en uso» y el «valor de cambio» o precio de las cosas. Pero condenó la usura, no llegando a entender jamás la importancia determinante que tiene el interés como precio de mercado que hace posible la coordinación entre el comportamiento de consumidores, ahorradores e inversores. Su teoría de la justicia es harto confusa, al distinguir entre dos dimensiones, la «distributiva» y la "conmutativa», que poco o nada tienen que ver con la adecuación del comportamiento humano a principios generales del derecho y la moral, y que al basarse en supuestas equivalencias han venido confundiendo el pensamiento humano sobre tan importante tema prácticamente hasta hoy. Además, una ilustración casi perfecta de que nunca entendió el orden evolutivo y espontáneo del mercado es su convicción de que jamás podría llegar a subsistir una polis de más de cien mil habitantes, ante la imposibilidad de su gobierno de organizarla. $Y$ es que Aristóteles tan sólo entiende la polis como un ente autosuficiente y organizado desde arriba (autarkía) y no como una plasmación histórica del proceso espontáneo de cooperación social protagonizado por seres humanos de carne y hueso dotados de una innata capacidad empresarial. Por último, Aristóteles sigue la tradición socrática de menospreciar el trabajo y el beneficio 
empresarial que, de forma anónima y descentralizada, permitió el elevado estadio de civilización que precisamente hizo posible que tanto él como el resto de los filósofos pudieron sobrevivir.

Por otro lado, Aristóteles también fracasó a la hora de explicar las razones del intercambio, concluyendo erróneamente que cuando el mismo se lleva a cabo es porque existen proporciones iguales entre cosas conmensurables (error que, en última instancia, sería posteriormente utilizado por Marx para fundamentar la falsa teoría del valor-trabajo y, su corolario, la teoría marxista de la explotación). Aristóteles desconfió de la riqueza (ploutos) criticando expresamente el beneficio empresarial (así, en su Política, número 7), minusvalorando y ninguneando a los comerciantes (Política, números 3 y 4). También condenó el interés (tokos) considerando que era una injustificada generación de dinero a partir del dinero. Además, su incapacidad para entender el surgimiento espontáneo de las instituciones le llevó a afirmar que el dinero fue un invento deliberado del ser humano (y no, como de hecho fue, el resultado de un proceso evolutivo), no entendiendo tampoco el porqué la demanda de dinero nunca es ilimitada. Todos estos errores de Aristóteles contrastan, sobre todo teniendo en cuenta su brillantez intelectual, con sus grandes aportaciones en el campo de las otras ciencias y en especial, en el ámbito de la epistemología.

En efecto, aunque Aristóteles comparte los errores de Sócrates y Platón al no entender el derecho consuetudinario, ni el mercado, ni el resto de las instituciones sociales como órdenes espontáneos, siendo igualmente incapaz de distinguir entre la sociedad civil y el estado (distinción que dos siglos después entenderán perfectamente los estoicos romanos), existe un campo, el de la epistemología, donde sus aportaciones son trascendentales. Su distinción entre potencia y acto se aplicará, siglos después, incluso para entender la plasmación evolutiva de la naturaleza del ser humano. Su concepción sobre las esencias formales y su plasmación específica material servirá de base para la distinción epistemológica entre la teoría y la historia a la vez que hará posible su adecuada incardinación. Y ya más cerca del campo de la economía debe reconocerse la aproximación aristotélica a la concepción subjetiva del valor, y en concreto su 
distinción entre el concepto de valor de uso (subjetivo) y valor de cambio (precio de mercado en unidades monetarias) que de alguna forma constituye el fundamento de la conexión entre el mundo subjetivo interior de las valoraciones y el mundo objetivo exterior de los cómputos numéricos que hace posible el cálculo económico. Finalmente, frente al estatismo socialista de Sócrates, y sobre todo de Platón, Aristóteles efectúa una defensa racional de la propiedad privada que, aunque incompleta y tibia, habrá de constituir durante muchos siglos el más conocido fundamento filosófico de la misma.

\section{$\mathrm{V}$ \\ BREVE NOTA SOBRE EL TAOISMO}

Por último, es de gran interés recordar que, durante los mismos años en los que se fraguaba el pensamiento clásico griego (siglos VI al IV a.C.), surgían en la antigua China tres grandes corrientes de pensamiento: la de los llamados «legalistas» (partidarios del estado central), los confucianos (tolerantes con el mismo), y la de los taoistas, de orientación mucho más liberal y del máximo interés para la historia del pensamiento económico. Así, Chiang Tzu (369 a 286 a.C.), llega a afirmar que «el buen orden surge espontáneamente cuando se deja a las cosas solas», criticando el intervencionismo de los gobernantes a los que califica de «ladrones». Tzu fue además, de acuerdo con Rothbard, el primer pensador anarquista. En efecto, Tzu llegó a escribir que el mundo «no necesita sencillamente ningún gobierno; de hecho no debería ser gobernado en forma alguna».

Chuang Tzu siguió y llevó hasta sus conclusiones más lógicas el liberalismo individualista del padre del taoismo, Lao Tzu, el cual, en época de Confucio (siglos VI-V a.C.) concluyó que el gobierno oprimía al individuo y era siempre "peor que el tigre más feroz», de forma que consideraba que la política más adecuada de un gobierno era la «inacción», pues solo ella permitía al individuo prosperar y alcanzar la felicidad.

Dos siglos después el historiador Ssu-ma Ch'ien (145-90 a.C.) teorizó sobre la función empresarial típica del mercado que para 
él consiste en «tener una vista aguda para atrapar las oportunidades que llegan». Además de teórico del laissez faire, enunció correctamente el impacto que tenía el envilecimiento de la moneda por el estado, al hacer disminuir su poder adquisitivo (es decir, subir los precios).

El taoismo siguió desarrollándose durante siglos y ya en nuestra era destaca la figura de Pao Ching-Yen (comienzos del siglo IV) para el cual la historia del estado es la historia de la violencia y de la opresión a los débiles. El estado institucionaliza la coacción y agrava e intensifica los hechos aislados de violencia, generalizándolos a una escala inimaginable si el estado no existiera. Pao Ching-Yen concluye que la idea común de que un estado fuerte es necesario para combatir el desorden cae en el error de confundir la causa con el efecto. Es el estado el que genera la violencia y corrompe el comportamiento individual de los seres humanos a él sometidos, estimulando el robo y el bandidaje.

En agudo contraste con el pensamiento de los filósofos griegos y del resto de los intelectuales occidentales hasta hoy, el pensamiento taoista chino siempre defendió la libertad individual y el laissez faire, criticando el ejercicio coactivo de la violencia ejercida sistemáticamente por los gobiernos. 